OTOLOGY

\title{
Anatomical and functional results of ossiculoplasty using titanium prosthesis
}

\author{
Risultati anatomici e funzionali dell'ossiculoplastica con protesi in titanio

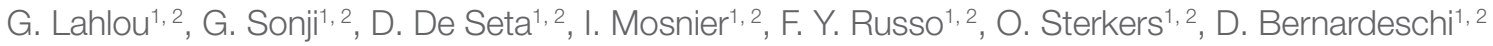 \\ ${ }^{1}$ AP-HP, Pitié-Salpêtrière Hospital, Otology, Auditory Implants and Skull Base Surgery Department, Paris, France; \\ 2 INSERM UMR-S 1159, "Mini-invasive and Robot-based Surgical Rehabilitation of Hearing", Paris, France
}

\section{SUMMARY}

Titanium ossicular chain replacement prosthesis is often used for rehabilitation of the columellar effect in otologic surgeries. This retrospective study aims to analyse the anatomical and functional results of surgeries in which a titanium prosthesis was used. Two hundred and eighty procedures in 256 patients operated on in a tertiary referral center were analysed. Aetiologies, preoperative audiograms, peroperative data and postoperative outcomes at 2 and 12 months postoperatively were reviewed. Chronic suppurative otitis media with or without cholesteatoma was the main aetiology (89\%). There was no difference in anatomical results between partial and total ossicular replacement prosthesis, with an overall dislocation rate of $6 \%$, and an overall extrusion rate of $3 \%$. Regarding functional results, a postoperative air-bone gap $\leq 20 \mathrm{~dB}$ was achieved in $65 \%$ of cases, with a better result for partial compared to total ossiculoplasty $(\mathrm{p}=0.02)$. A significant difference in air bone gap closure was found when comparing aetiologies, with a higher air-bone gap closure in malformation cases compared to chronic suppurative otitis media with cholesteatoma or retraction cases $(\mathrm{p}=0.03)$. Ossiculoplasty using titanium prosthesis is a safe and effective procedure for rehabilitation of hearing loss, which allows reaching an air-bone gap $\leq 20 \mathrm{~dB}$ in the majority of patients.

KEY WORDS: Ossiculoplasty • Chronic suppurative otitis media with cholesteatoma $\bullet$ Malformation $\bullet$ Ossicular chain $\bullet$ Otology

\section{RIASSUNTO}

Le protesi ossiculari in titanio sono sempre più frequentemente utilizzate per ristabilire la continuità della catena ossiculare nella chirurgia otologica. Il presente studio retrospettivo ha come scopo quello di analizzare i risultati anatomici e funzionali di questa tecnica. Sono state studiate 280 procedure di ossiculoplastica con protesi in titanio, realizzate su 256 pazienti in un centro ospedaliero universitario. Sono stati raccolti e analizzati i dati riguardanti l'eziopatogenesi, l'audiometria preoperatoria e i risultati postoperatori anatomici e audiologici a 2 e 12 mesi. La prima patologia riscontrata in ordine di frequenza è stata l'otite cronica con o senza colesteatoma (80\% dei casi), ma non è stata riscontrata nessuna differenza significativa nei dati audiologici preoperatori in funzione della patologia. Nel $65 \%$ dei casi è stato raggiunto nel postoperatorio un gap aereo $\leq 20 \mathrm{~dB}$, con risultati significativamente migliori nelle ossiculoplastiche parziali rispetto alle totali $(p=0,02)$. Al contrario, per quanto riguarda i risultati anatomici non è stata riscontrata alcuna differenza utilizzando le protesi parziali o totali, con un tasso globale di dislocazione del $6 \%$ e di estrusione della protesi del 3\%. È stata trovata una differenza significativa nei risultati audiologici postoperatori in funzione della patologia otologica di base, con una variazione maggiore del gap aereo nei casi di malformazione rispetto ai casi di otite cronica colesteatomatosa o patologia retrattiva $(p=0,03)$. Ne consegue che il tipo di chirurgia non influenza il risultato postoperatorio. L'ossiculoplastica con protesi in titanio si è rivelata una procedura valida ed efficace che permette un miglioramento dell'udito postoperatorio nella maggior parte dei pazienti.

PAROLE CHIAVE: Ossiculoplastica $\bullet$ Colesteatoma $\bullet$ Malformazione $\bullet$ Catena ossiculare $\bullet$ Otologia

Acta Otorhinolaryngol Ital 2018;38:377-383

\section{Introduction}

Restoring a columellar effect with ossiculoplasty for rehabilitation of hearing loss in case of ossicular chain discontinuity is one of the main objectives of tympanoplasty procedures. Different materials are used for ossiculoplas- ty, including homologous materials (ossicules, cartilage) and synthetic materials (plastipore, ceravital, hydroxyapatite, metal, titanium) ${ }^{12}$. Titanium has many advantages in terms of biocompatibility, weight and acoustic performance ${ }^{3-5}$. It is also compatible with MRI at 1.5 and 3 te- 
sla ${ }^{67}$, which is of primary importance, especially in cholesteatoma surgery. Many studies have shown that titanium prosthesis gave better anatomical and functional results than autologous materials ${ }^{89}$, and the results seem to be comparable to those with hydroxyapatite prosthesis ${ }^{1011}$.

Despite many reports describing encouraging results with the use of titanium prosthesis, we aimed to analyse the anatomical and functional results of a large series of patients operated on for ossiculoplasty; moreover, we aimed to look for prognostic factors influencing these results.

\section{Materials and methods}

\section{Study design}

All patients operated on for an ossiculoplasty from January 2004 to December 2008 in a tertiary referral centre were retrospectively reviewed. This study was authorised by the local institutional review board (CPP Île-de-France VI) and all patients gave their informed consent to the use of clinical data. Two hundred and eighty procedures in 256 patients were included. Titanium prosthesis were used in all procedures. All patients had a preoperative audiometric test and at least a postoperative test 8 weeks after surgery. Preoperative assessment included otoscopy, pure-tone audiometry with headphone and HRCT-scan study. Post-operative assessment included anatomical results with otoscopy (presence of a well-healed tympanic membrane), functional results (audiometry) and complications (residual perforation of the tympanic membrane, retraction, cholesteatoma recurrence, prosthesis extrusion, or displacement).

\section{Audiometric assessment}

Preoperative and postoperative data were recorded according to the American Academy of OtolaryngologyHead and Neck Surgery (AAO-HNS) standards ${ }^{12}$. Audiometric outcomes were recorded at 2 months and 12 months after surgery.

Air conduction (AC) and bone conduction (BC) thresholds were recorded. Thresholds at 500; 1,000; 2,000 and $3,000 \mathrm{~Hz}$ were used to calculate the pure-tone average (PTA). If the $3,000 \mathrm{~Hz}$ threshold was not available, it was calculated as the mean between 2,000 and 4,000 Hz. The preoperative and postoperative Air-Bone Gap (ABG) were calculated as BC PTA minus AC PTA. The differences between the preoperative and the postoperative ABG (ABG closure) were recorded and noted as $\triangle \mathrm{ABG}$. The differences between the preoperative and the postoperative $\mathrm{BC}$ threshold at 4,000 Hz were calculated; postoperative labyrinthisation was defined by a difference of more than $30 \mathrm{~dB}$.

\section{Surgery}

A retroauricular approach was used in 248 cases $(88 \%)$, and a trans-canal approach through an ear speculum in 32 cases $(12 \%)$. The procedure started with systematic exploration of the middle ear, with attico-mastoidectomy in case of cholesteatoma, using a canal-wall-up (CWU) technique whenever possible. Ossiculoplasty was performed in a one-stage procedure, even in the case of cholesteatoma ${ }^{13}$. Kurz ${ }^{\circledR}$ (Heinz Kurz GmbH Medzintechnik, Dusslingen, Germany) titanium Bell partial ossicular replacement prosthesis (PORP) was used when the stapes superstructure was mobile and intact (Fig. 1A). Kurz ${ }^{\circledR}$ titanium Aerial total ossicular replacement (TORP) was used when the stapes was absent (Fig. 1B). In case of fixed stapes footplate, a stapedotomy with perichondrium or fascia temporalis interposition was achieved and the TORP was then positioned. The AC-sizer system was used in all cases to choose the length of the prosthesis.

A thinned cartilage graft was placed in all cases between the tympanic membrane and the head plate of the prosthesis (Fig. 2). Furthermore, in 187 cases (67\%), the tympanic membrane was reinforced by a cartilage graft. At the end of the procedure, the tympanomeatal flap was positioned, and pieces of Merogel ${ }^{\circledR}$ (Medtronic Xomed, Jecksonville, FL) and an ear wick were placed above it. The ear wick was removed one week later. All patients had post-operative eardrops of ofloxacine for 2 weeks.

\section{Statistical analysis}

Results are presented as mean \pm standard deviation (SD). Statistical tests were performed using Statview (SAS Inc. Carey). Fisher test, ANOVA, Bonferroni, and t-test were used depending on data compared. Differences were considered statistically significant when $\mathrm{p}<0.05$.

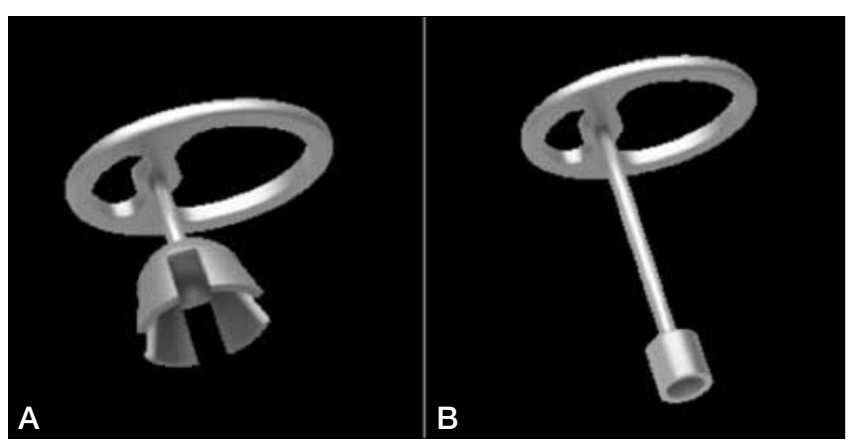

Fig. 1. Partial (A) and total (B) ossicular replacement prosthesis used in this study. 


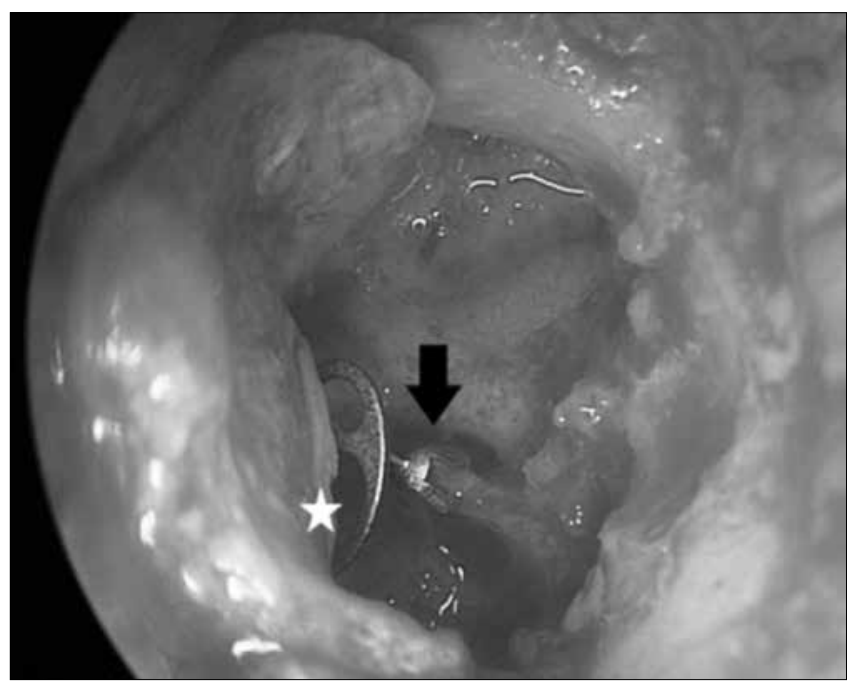

Fig. 2. An endoscopic view of a right ear undergoing a canal-wall-down tympanoplasty with cartilage graft (white star) and partial ossicular replacement prosthesis (black arrow).

\section{Results}

Two hundred and eighty procedures in 256 patients were included. The mean age was $44 \pm 14$ years (17-74). Demographic data, aetiologies and surgical procedures are detailed in Table I. Chronic suppurative otitis media with or without cholesteatoma and retraction pocket were the main aetiologies, with $89 \%$ of cases (Table I). Other aeti- ologies were revision surgery for otosclerosis with a lysis of the long process of the uncus, traumatism, ossicular malformation and middle ear tumours (one paraganglioma and two facial nerve schwannomas).

Preoperatively, the mean PTA was $50 \pm 18.1 \mathrm{~dB}$, and the mean $\mathrm{ABG}$ was $27 \pm 11.9 \mathrm{~dB}$. There was no difference in preoperative audiologic data between aetiology (ANOVA and Bonferroni tests) (Table II).

PORP were used in 163 cases (58\%), and TORP were used in 117 cases (42\%). Stapedotomy with perichondrium or fascia interposition was necessary in 10 cases (9\%) in the TORP group in case of a fixed stapes footplate. The mean preoperative $\mathrm{ABG}$ was $26 \pm 10.5 \mathrm{~dB}$ in PORP group and $30 \pm 13.2 \mathrm{~dB}$ in TORP group $(\mathrm{p}=0.001$, $\mathrm{t}$-test $)$.

Postoperative outcomes were available for 280 procedures at 2 months postoperatively (100\%), and for 180 procedures at 12 months postoperatively (64\%).

\section{Anatomical results}

Residual perforations of the tympanic membrane were reported in 5 cases at 2 months $(2 \%)$ and in no case at 12 months. Three cases of postoperative retraction were noted at 12 months (1\%). At 12 months, extrusion of the prosthesis was present in 6 cases (3\%) and dislocation in 11 cases (6\%), of which 3 cases occurred before 2 months (Table III). All cases of extrusion or dislocation were described for patients with chronic suppurative otitis media with or without cholesteatoma. There was no significant

Table I. Demographic and pathological characteristics.

\begin{tabular}{|c|c|c|c|}
\hline & & $\mathbf{N}$ & $\%$ \\
\hline \multirow[t]{2}{*}{ Sex } & Men & 123 & 48 \\
\hline & Women & 133 & 52 \\
\hline \multirow[t]{2}{*}{ Side } & Right & 158 & 56.4 \\
\hline & Left & 122 & 43.6 \\
\hline \multirow[t]{7}{*}{ Causing pathology } & Chronic suppurative otitis media with cholesteatoma & 125 & 45 \\
\hline & Chronic suppurative otitis media & 85 & 30 \\
\hline & Retraction pocket & 40 & 14 \\
\hline & Traumatism & 12 & 4 \\
\hline & Otosclerosis (revision) & 11 & 4 \\
\hline & Malformation & 4 & 1 \\
\hline & Tumor & 3 & 1 \\
\hline \multirow[t]{6}{*}{ Surgery } & Revision surgery & 161 & 57 \\
\hline & Primary surgery & 119 & 43 \\
\hline & No mastoidectomy & 160 & 57 \\
\hline & CWU mastoidectomy & 74 & 26 \\
\hline & CWD mastoidectomy & 46 & 17 \\
\hline & Trans-canal atticotomy & 187 & 67 \\
\hline
\end{tabular}

CWU: canal-wall-up; CWD: canal-wall-down. 
Table II. Audiologic results depending on the pathology preoperatively, at 2 months, and at 12 months after surgery.

\begin{tabular}{|c|c|c|c|c|c|c|}
\hline \multirow[t]{2}{*}{ Pathology } & \multicolumn{3}{|c|}{ PTA } & \multicolumn{3}{|c|}{$A B G$} \\
\hline & Pre & 2 months & 12 months & Pre & 2 months & 12 months \\
\hline $\begin{array}{l}\text { All Chronic suppurative otitis media } \\
\text { with cholesteatoma }(n=125)\end{array}$ & $49 \pm 18.4$ & $40 \pm 13.3$ & $40 \pm 14.9$ & $27 \pm 11.9$ & $19 \pm 10.5$ & $18.7 \pm 10.5$ \\
\hline $\begin{array}{l}\text { Recurent chronic suppurative otitis media } \\
\text { with cholesteatoma }(n=54)\end{array}$ & $52 \pm 19.3$ & $43 \pm 19.3$ & $43 \pm 20.7$ & $30 \pm 12.8$ & $21 \pm 11.8$ & $19 \pm 10.9$ \\
\hline $\begin{array}{l}\text { Chronic suppurative otitis media } \\
(n=85)\end{array}$ & $54 \pm 17.8$ & $43 \pm 19.5$ & $45 \pm 19.5$ & $30 \pm 10.9$ & $18 \pm 11.2$ & $18 \pm 10.9$ \\
\hline Retraction pocket $(n=40)$ & $44 \pm 14.9$ & $37 \pm 14.6$ & $38 \pm 19.8$ & $22 \pm 10.1$ & $17 \pm 8.9$ & $15 \pm 10.3$ \\
\hline Traumatism $(n=12)$ & $51 \pm 20.5$ & $33 \pm 17.1$ & $29 \pm 17.1$ & $25 \pm 14.8$ & $13 \pm 9.3$ & $10 \pm 9.1$ \\
\hline Otosclerosis $(n=11)$ & $55 \pm 4.4$ & $44 \pm 16.4$ & $39 \pm 14.3$ & $26 \pm 10.1$ & $15 \pm 10.2$ & $15 \pm 10.1$ \\
\hline Malformation $(n=4)$ & $55 \pm 15.4$ & $28 \pm 21.1$ & $19 \pm 6.9$ & $37 \pm 12.2$ & $10 \pm 5.3$ & $7 \pm 1.9$ \\
\hline Tumour $(\mathrm{n}=3)$ & $32 \pm 21.9$ & $35 \pm 7.3$ & $26 \pm 8.9$ & $12 \pm 9.5$ & $10 \pm 5.1$ & $12 \pm 7.1$ \\
\hline
\end{tabular}

PTA = Pure-Tone Average; $A B G=$ Air-Bone Gap.

Table III. Anatomic and audiological outcomes depending on the surgical technique at 12 months after surgery.

\begin{tabular}{|c|c|c|c|c|c|c|c|c|c|c|}
\hline & \multicolumn{3}{|c|}{ 0ssicular prosthesis } & \multicolumn{3}{|c|}{ Primary or revision } & \multicolumn{4}{|c|}{ Mastoidectomy } \\
\hline & $\begin{array}{c}\text { PORP } \\
(n=106)\end{array}$ & $\begin{array}{c}\text { TORP } \\
(n=74)\end{array}$ & $p$ & $\begin{array}{l}\text { Primary } \\
(\mathrm{n}=77)\end{array}$ & $\begin{array}{l}\text { Revision } \\
(n=103)\end{array}$ & $\mathrm{p}$ & $\begin{array}{c}\text { No } \\
(n=109)\end{array}$ & $\begin{array}{c}\text { CWU } \\
(n=45)\end{array}$ & $\begin{array}{c}\text { CWD } \\
(n=26)\end{array}$ & $p$ \\
\hline $\begin{array}{l}\text { Preoperative } \\
\text { ABG (dB) }\end{array}$ & $26 \pm 10.5$ & $30 \pm 13.2$ & 0.001 & $25 \pm 11.6$ & $29 \pm 11.9$ & 0.03 & $26 \pm 11.9$ & $24 \pm 9.7$ & $33 \pm 12.8$ & 0.03 \\
\hline $\begin{array}{l}\text { Dislocation N } \\
(\%)\end{array}$ & $3(3)$ & $8(11)$ & 0.05 & $6(7.8)$ & $5(4.9)$ & 0.5 & $5(5)$ & $5(11)$ & $1(4)$ & 0.2 \\
\hline $\begin{array}{l}\text { Extrusion } \\
\mathrm{N}(\%)\end{array}$ & $2(2)$ & $4(5)$ & 0.2 & $4(5)$ & $2(2)$ & 0.4 & $3(3)$ & $2(4)$ & $1(4)$ & 0.8 \\
\hline $\begin{array}{l}\text { Surgical success } \\
\mathrm{N}(\%)\end{array}$ & $76(72)$ & $41(55)$ & 0,02 & $58(75)$ & $59(57)$ & 0.02 & $74(68)$ & $34(76)$ & $9(35)$ & 0.002 \\
\hline $\begin{array}{l}\text { ABG closure } \\
(\mathrm{dB})\end{array}$ & $11 \pm 1.1$ & $10 \pm 1.5$ & $>0.5$ & $11 \pm 1.5$ & $10 \pm 1$ & $>0.5$ & $12 \pm 1.1$ & $11 \pm 1.8$ & $7 \pm 1.9$ & 0.07 \\
\hline
\end{tabular}

$\overline{A B G}=$ Air-Bone Gap; $C W U$ = Canal-Wall-Up; $C W D=$ Canal-Wall-Down .

difference in extrusion rate or dislocation rate for TORP and PORP group at 12 months (Fisher tests), although the rate of dislocation was higher for TORP $(n=8,11 \%)$ compared to PORP ( $\mathrm{n}=3,3 \%)(\mathrm{p}=0.05$, Fisher test). There was no difference in extrusion rate or dislocation rate comparing primary or a revision surgery, even for recurrent cholesteatoma (Fisher test) (Table III).

\section{Audiometric results}

The mean PTA was $40 \pm 18.3 \mathrm{~dB}$ and $40 \pm 19.5 \mathrm{~dB}$ at 2 months and 12 months after surgery, respectively. The mean $\mathrm{ABG}$ was $18 \pm 10.5 \mathrm{~dB}$ at 2 months after surgery and $17 \pm 10.6 \mathrm{~dB}$ at 12 months after surgery. Table II shows the audiometric results depending on the pathology.

Surgical success, defined as a postoperative $A B G \leq 20 \mathrm{~dB}$, was observed in $59 \%(\mathrm{n}=166)$ of cases at 2 months postoperatively, and in $65 \%(\mathrm{n}=117)$ of cases at 12 months after surgery. There was a significant difference between the
PORP group and the TORP group at 2 and 12 months after surgery: at 2 months, surgical success was achieved for 108 cases (66\%) in the PORP group and in 57 cases (49\%) in the TORP group ( $\mathrm{p}=0.004$, Fisher test); at 12 months, it was achieved for 76 procedures (72\%) in the PORP group and in 41 cases $(55 \%)$ in the TORP group ( $p=0.02$, Fisher test). There was no difference in ABG closure in the PORP and TORP groups. At 2 months, mean ABG closure was $9 \pm 0.8 \mathrm{~dB}$ in the PORP group and $9 \pm 1.2 \mathrm{~dB}$ in the TORP group ( $p>0.5$, t-test). At 12 months, the mean ABG closure was $11 \pm 1.1 \mathrm{~dB}$ in the PORP group, and $10 \pm 1.5 \mathrm{~dB}$ in the TORP group ( $p>0.5$, t-test). A difference in ABG closure at 2 months after surgery was found depending on the pathology (Fig. 3): ABG closure in malformation cases was significantly greater than in cholesteatoma cases (respectively $27 \pm 10.7$ and $7 \pm 11.7$; $=0.03$, t-test) and retraction cases (respectively $27 \pm 10.7$ and $5 \pm 9.5 ; \mathrm{p}=0.02$, t-test). This difference was not significant at 12 months $(\mathrm{p}=0.06$, $\mathrm{t}$-test $)$. 


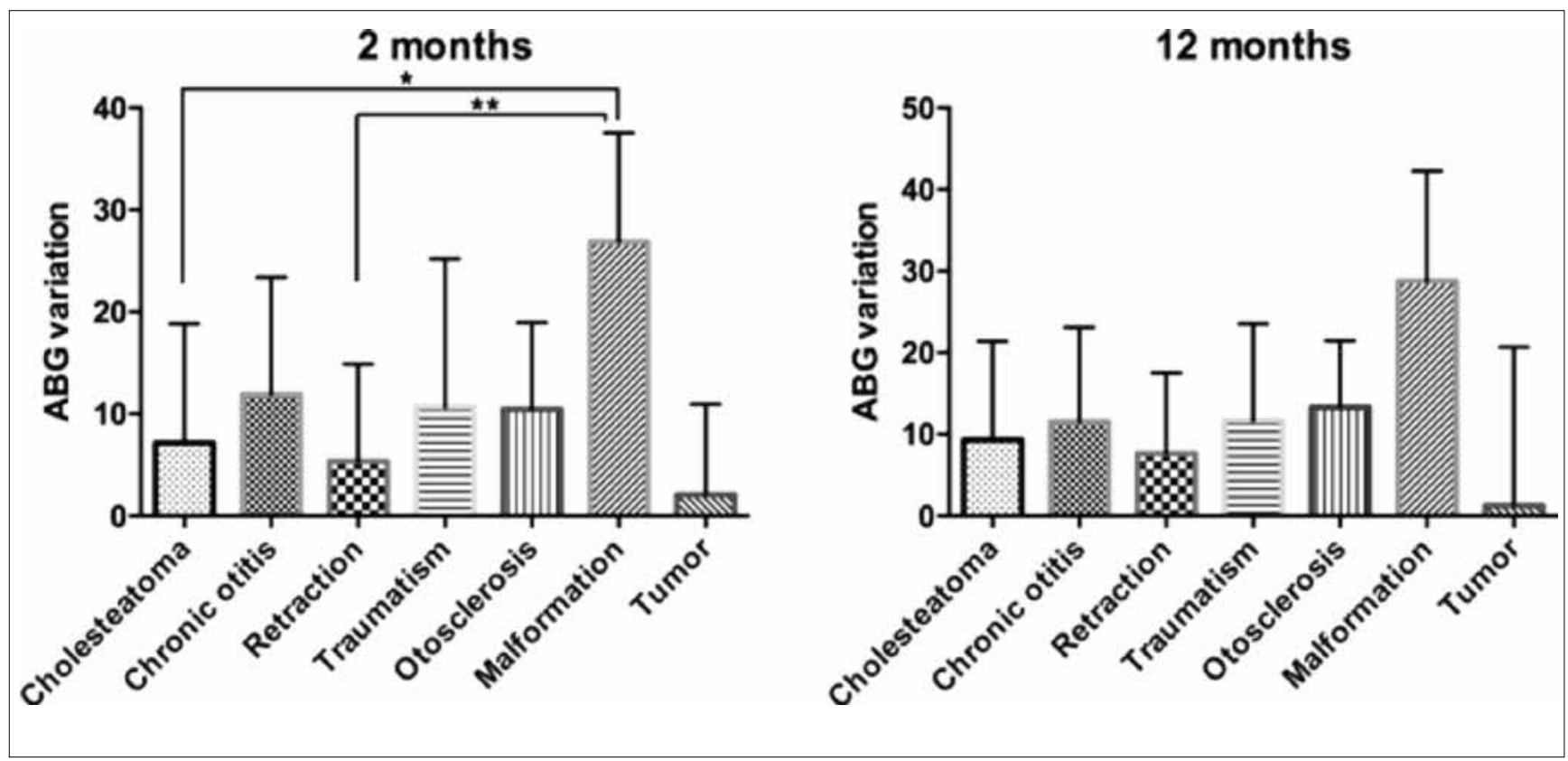

Fig. 3. ABG (Air-Bone Gap) variation depending on the causing pathology at 2 months and 12 months after surgery.

ABG closure was not significantly different in case of primary or revision surgery (t-test), although surgical success was significantly different (Table III): in case of primary surgery, ABG closure was $9 \pm 1.2 \mathrm{~dB}$ at 2 months after surgery, and $11 \pm 1.5 \mathrm{~dB}$ at 12 months after surgery. In case of revision surgery, $\mathrm{ABG}$ closure was $9 \pm 0.5 \mathrm{~dB}$ at 2 months after surgery, and $10 \pm 1 \mathrm{~dB}$ at 12 months after surgery.

Finally, ABG closure was not dependent on the surgical procedure, although surgical success was significantly different (Table III): there was no difference between patients operated on without mastoidectomy, with canal-wall-up, or with canal-wall-down mastoidectomy. At 12 months after surgery, the closure was, respectively, $12 \pm 1.1 \mathrm{~dB}$, $11 \pm 1.8 \mathrm{~dB}$ and $7 \pm 1.9 \mathrm{~dB}$ (non-significant, t-test).

Concerning postoperative labyrinthisation, there was no variation of the mean postoperative $\mathrm{BC}$ threshold at 2 and 12 months compared with the preoperative one (t-test), and no difference between the TORP and the PORP group for the postoperative BC thresholds (t-test). Labyrinthisation occurred in 1 cholesteatoma case.

\section{Discussion}

Titanium ossicular prosthesis are routinely used in otologic surgery and seem to give satisfactory postoperative anatomic and audiologic results. Globally, the literature reports surgical success, defined as $\mathrm{ABG}<20 \mathrm{~dB}$, between $56 \%$ and $81.4 \%$ in short-term studies (around 12 months of followup) ${ }^{14-22}$. These results are comparable to results presented in this study with $65 \%$ success at 12 months postoperatively. Some studies compared results obtained with titanium prosthesis to other materials: titanium appeared to give better audiologic results than gold ${ }^{23}$, ceravital ${ }^{23}$, or plastipore ${ }^{24}$. Also, ossiculoplasty with titanium prosthesis appears to be more succesfull than autologous materiel (ossicle or cartilage) ${ }^{89}$. The results with hydroxyapatite prosthesis are comparable to titanium prosthesis 101125 . Finally, cement ossiculoplasty seems to give similar results compared to partial prosthesis for incudostapedial, maleus to stapes re-bridging ${ }^{26}$.

The results presented in this study are also comparable for extrusion and dislocation rates, with $3 \%$ of extrusion and $6 \%$ of dislocation. In short-term studies, extrusions are estimated between 1 and 5\% 17192728 , with dislocation in 2\% of cases ${ }^{28}$. Long-term studies show more cases of dislocations (between 3.5 and $10.8 \%{ }^{162930}$ ). This can be caused either by a non-optimal prosthesis size, or by a recurrence of the causing pathology, especially retraction or cholesteatoma ${ }^{329}$. In this study, no difference in extrusion or dislocation rate was found for recurrent cholesteatoma compared to other aetiologies, but the follow-up ends at 12 months postoperative. Concerning extrusions, they seem to appear earlier after surgery. All cases in this study were seen early, at 2 months after surgery, and long-term studies also show that extrusions appear in the first year after surgery ${ }^{329}$.

This study reports results comparable to others in terms of hearing and anatomical results, even if all procedures were one-stage procedures, even in case of cholesteatoma. 
This result should be confirmed in a long-term study, but for adult ossiculoplasty, it seems that there is no need to postpone the reconstruction procedure for further surgery. There was no difference between PORP and TORP group concerning extrusion or dislocation rate. Other studies in literature show the same result with no more dislocation or extrusion using TORP or PORP ${ }^{31}{ }^{32}$. Conversely, a difference in audiologic results was observed for postoperative $\mathrm{ABG}$, with a better result for the PORP group compared to the TORP group, with surgical success significantly higher for former group. This has to take into account that preoperative $A B G$ is also better in the PORP group compared to the TORP group, and that there is no difference in $\mathrm{ABG}$ closure between the two groups. This observation suggests that the presence of the stapes superstructure could be important for audiologic results, even if anatomic results are as good for the TORP group as for the PORP group. This could be due to the fact that the absence of the stapes superstructure is usually associated with a more extensive disease, which causes an adverse environment for reconstruction. This result was also observed in the literature in most studies using a titanium $^{5163132}$ or hydroxyapatite prosthesis ${ }^{2}$. In a meta-analysis on a total of 4311 procedures, the superiority of PORP of postoperative $\mathrm{ABG}$ was confirmed with a combined RR of 1.28 (95\% CI 1.17-1.41) ${ }^{31}$. Thus, this observation is controverted in literature, and other studies showed no difference between results obtained with PORP or TORP ${ }^{15} 29$.

In addition to the type of reconstruction, the causing pathology also seems to be a prognostic factor for the postoperative audiologic result. This study showed very good functional results in case of malformation and poorer results in case of cholesteatoma or retraction pocket. In addition to malformation cases, $\mathrm{ABG}$ gain seems to be around $10 \mathrm{~dB}$ after surgery. ABG gain was greater for malformation cases, but this difference was not significant at 12 months, probably because of the low statistical power due to patients lost during follow-up. Despite this, ABG outcomes seem to be worse in case of chronic suppurative otitis media with or without cholesteatoma (Table II). Gelfand and Chang also found that cholesteatoma or tympanic perforation had a negative impact on the audiologic results ${ }^{11}$. In a longer-term study, Hess-Erga et al. showed that patients without chronic suppurative otitis media media tend to have better audiologic results than patients with chronic suppurative otitis media ${ }^{3}$. Becvarovski described the Middle Ear Risk Index (MERI) that includes poor prognosis factors for middle ear surgery: cholesteatoma, perforation, otorrhoea, granulation, ossicular lysis, revision surgery and smoking ${ }^{33}$. Two studies then showed that cases with a high risk according to the MERI were associated with poorer audiologic results $(\triangle \mathrm{ABG}){ }^{34}{ }^{35}$.
These studies also showed a deleterious effect of the surgical technique, particularly if mastoidectomy or CWD was used. Unlike these studies, ours shows no effect of the type of surgery on audiologic results, and revision surgery was not related to a poorer result, but this could be because of a lack of statistical power herein.

This study has certain limitations. First, it reports only shortterm outcomes of titanium ossiculoplasty, and it would be interesting to look for long term results. In fact, O'Connell et al. showed a significant increase between short-term and long-term results for $\mathrm{ABG}^{29}$. Additionally, they showed that surgical revisions were all performed more than 2 years after the first surgery ${ }^{29}$. Second, it is a retrospective study, with a significant proportion of patients lost to follow-up. This could introduce some bias in the results at 12 months.

\section{Conclusions}

Ossiculoplasty using titanium prosthesis is a safe and effective procedure both anatomically or functionally. This study suggests that using a PORP gives better results in terms of hearing compared to TORP, and that inflammatory pathologies of the middle ear also have a negative impact on audiologic results. All these results must be confirmed during longer follow-up, which would permit observing stability of outcomes over time.

\section{References}

1 Baylancicek S, Iseri M, Topdağ DÖ, et al. Ossicular reconstruction for incus long-process defects: bone cement or partial ossicular replacement prosthesis. Otolaryngol Neck Surg 2014;151:468-72.

2 Rondini-Gilli E, Grayeli AB, Borges Crosara PFT, et al. Ossiculoplasty with total hydroxylapatite prostheses anatomical and functional outcomes. Otol Neurotol 2003;24:543-7.

3 Hess-Erga J, Møller P, Vassbotn FS. Long-term hearing result using Kurz titanium ossicular implants. Eur Arch Otorhinolaryngol 2013;270:1817-21.

4 Zenner HP, Freitag HG, Linti C, et al. Acoustomechanical properties of open TTP? Titanium middle ear prostheses. Hear Res 2004;192:36-46.

5 Quesnel S, Teissier N, Viala P, et al. Long term results of ossiculoplasties with partial and total titanium Vario Kurz prostheses in children. Int J Pediatr Otorhinolaryngol 2010;74:1226-9.

6 Martin AD, Driscoll CLW, Wood CP, et al. Safety evaluation of titanium middle ear prostheses at 3.0 tesla. Otolaryngol Head Neck Surg 2005;132:537-42.

7 Kwok P, Waldeck A, Strutz J. How do metallic middle ear implants behave in the MRI? Laryngorhinootologie 2003;82:13-8.

8 Zakzouk A, Bonmardion N, Bouchetemble P, et al. Titanium prosthesis or autologous incus for total ossicular reconstruc- 
tion in the absence of the stapes suprastructure and presence of mobile footplate. Eur Arch Otorhinolaryngol 2014;272:2653-7.

9 Orfao T, Julio S, Ramos JF, et al. Audiometric outcome comparison between titanium prosthesis and molded autologous material. Otolaryngol Head Neck Surg 2014;151:315-20.

10 Yung M, Smith P. Titanium versus nontitanium ossicular prostheses-a randomized controlled study of the mediumterm outcome. Otol Neurotol 2010;31:752-8.

11 Gelfand YM, Chang CYJ. Ossicular chain reconstruction using titanium versus hydroxyapatite implants. Otolaryngol Head Neck Surg 2011;144:954-8.

12 American Academy of Otolaryngology Head and Neck Surgery Foundation. Committee on Hearing and Equilibrium guidelines for the evaluation of hearing preservation in acoustic neuroma (vestibular schwannoma). Otolaryngol Head Neck Surg 1995;113:179-80.

13 Rondini-Gilli E, Mosnier I, Julien N, et al. One-stage surgery of middle ear cholesteatomain adults: apropos of 180 cases. Rev Laryngol Otol Rhinol (Bord) 2001;122:75-9.

14 Alaani A, Raut V. Kurz Titanium prosthesis ossiculoplasty - follow-up statistical analysis of factors affecting one year hearing results. Auris Nasus Larynx 2010;37:150-4.

15 De Vos C, Gersdorff M, Gerard J. Prognostic factors in ossiculoplasty. Otol Neurotol 2006;28:61-7.

16 Schmerber S, Troussier J, Dumas G, et al. Hearing results with the titanium ossicular replacement prostheses. Eur Arch Otorhinolaryngol 2006;263:347-54.

17 Ho SY, Battista RA, Wiet RJ. Early results with titanium ossicular implants. Otol Neurotol 2003;24:149-52.

18 Dalchow CV, Grün D, Stupp HF. Reconstruction of the ossicular chain with titanium implants. Otolaryngol Head Neck Surg 2001;125:628-30.

19 Vassbotn FS, Møller P, Silvola J. Short-term results using Kurz titanium ossicular implants. Eur Arch Otorhinolaryngol 2007;264:21-5.

20 Bernardeschi D, Pyatigorskaya N, Russo F, et al. Anatomical, functional and quality-of-life results for mastoid and epitympanic obliteration with bioactive glass $553 p 4$ : a prospective clinical study. Clin Otolaryngol 2017;42:387-96.

21 Bernardeschi D, Nguyen Y, Russo FY, et al. Cutaneous and labyrinthine tolerance of bioactive glass S53P4 in mastoid and epitympanic obliteration surgery: prospective clinical study. Biomed Res Int 2015;2015:242319.
22 Bernardeschi D, Nguyen Y, Mosnier I, et al. Use of granules of biphasic ceramic in rehabilitation of canal wall down mastoidectomy. Eur Arch Otorhinolaryngol 2014;271:59-64.

23 Zenner HP, Stegmaier A, Lehner R, et al. Open Tübingen titanium prostheses for ossiculoplasty: a prospective clinical trial. Otol Neurotol 2001;22:582-9.

24 Neff B, Rizer FM, Schuring AG, et al. Tympano-ossiculoplasty utilizing the spiggle and theis titanium total ossicular replacement prosthesis. Laryngoscope 2003;113:1525-9.

25 Truy E, Naiman AN, Pavillon C, et al. Hydroxyapatite versus titanium ossiculoplasty. Otol Neurotol 2007;28:492-8.

26 Gungor V, Atay G, Bajin MD, et al. Comparison of various bone cement ossiculoplasty techniques and functional results. Acta Otolaryngol 2016;6489:1-5.

27 Martin AD, Harner SG. Ossicular reconstruction with titanium prosthesis. Laryngoscope 2004;114:61-4.

28 Meulemans J, Wuyts FL, Forton GEJ. Middle ear reconstruction using the titanium kurz variac partial ossicular replacement prosthesis. JAMA Otolaryngol Neck Surg 2013;139:1017.

29 O 'connell BP, Rizk HG, Hutchinson T, et al. Long-term outcomes of titanium ossiculoplasty in chronic otitis media. Otolaryngol Neck Surg 2016;1-9.

${ }^{30}$ Quaranta N, Zizzi S, Quaranta A. Hearing results using titanium ossicular replacement prosthesis in intact canal wall tympanoplasty for cholesteatoma. Acta Otolaryngol 2011;131:36-40.

$31 \mathrm{Yu} \mathrm{H}, \mathrm{He}$ Y, Ni Y, et al. PORP vs TORP: a meta-analysis. Eur Arch Otorhinolaryngol 2013;270:3005-17.

32 Vincent R, Rovers M, Mistry N, et al. Ossiculoplasty in intact stapes and malleus patients: a comparison of PORPs versus TORPs with malleus relocation and Silastic banding techniques. Otol Neurotol 2011;32:616-25.

33 Becvarovski Z, Kartush JM. Smoking and tympanoplasty: implications for prognosis and the middle ear risk index (MERI). Laryngoscope 2001;111:1806-11.

34 Demir UL, Karaca S, Ozmen OA, et al. Is it the middle ear disease or the reconstruction material that determines the functional outcome in ossicular chain reconstruction? Otol Neurotol 2012;33:580-5.

35 Felek S, Celik H, Islam A, et al. Type 2 ossiculoplasty: prognostic determination of hearing results by middle ear risk index. Am J Otolaryngol 2010;31:325-31.

Address for correspondence: Daniele Bernardeschi, Otology, Auditory Implants and Skull Base Surgery Department, Pitié-Salpêtrière Hospital, bd Vincent Auriol 50/52, 75013 Paris, France. Tel. +33 (0)1 421626 03. Fax + 33 (0)1 421626 05. E-mail: daniele.bernardeschi@aphp.fr 